\title{
Solitary Temporal Plasmocytoma: A Case Report
}

\author{
Oufaa Jamal, Abderrahmane Rafiq, Tarek Misbahi, and Adelhakim Lakhdar
}

\section{ABSTRACT}

Introduction: Solitary plasmacytoma is a malignant plasma cell tumor that is much rarer than multiple myeloma. The location in the vault of plasmacytoma is extremely rare. We report the case of a plasmacytoma of the cranial vault in a 53-year-old adult.

Observation: A 53-year-old man consulted for tinnitus, left hypoacusis and trigeminal neuralgia of the left $\mathrm{V} 2$ and $\mathrm{V} 3$, which had been evolving for one year and was aggravated one month later by the appearance of a left temporal swelling with decreased visual acuity on the left. The MRI confirmed the existence of a lesional process of the temporal vault, in $\mathrm{T} 1$ iso signal, T2 hypersignal and flair, intensely and heterogeneously enhanced after injection of gadolinium. Anatomopathological study revealed a solitary temporal plasmacytoma, which was referred to oncology for further management.

Discussion: Plasmacytoma is defined as an isolated malignant plasma cell tumor without clinical, biological, or radiological signs of Myeloma. Craniocerebral localization is rare and constitutes only $0.7 \%$ of all solitary plasmacytomas.

Conclusion: Cranial plasmacytoma is a rare tumor that should be investigated for associated myeloma. Although the imaging appearance is not very specific, plasmacytoma should be considered in the differential diagnosis of any invasive lytic lesion of the cranial vault.

Keywords: A case report, cranial vault, CT, Kahler disease, MRI, solitary plasmacytoma.
Submitted : November 7, 2021

Published : December 7, 2021

ISSN: $2593-8339$

DOI: $10.24018 /$ ejmed.2021.3.6.1135

\section{O. Jamal}

Department of Neurosurgery, UHC

IBN Rochd Casablanca, Morocco.

(e-mail: oufaa.jamal@gmail.com)

A. Rafiq*

Department of Neurosurgery, UHC

IBN Rochd Casablanca, Morocco.

(e-mail: meryemfarisrafiq@ ${ }^{\circledR}$ gmail.com)

T. Misbahi

Department of Neurosurgery, UHC

IBN Rochd Casablanca, Morocco.

(e-mail: dr.t.mesbahi@gmail.com)

A. Lakhdar

Department of Neurosurgery, UHC

IBN Rochd Casablanca, Morocco.

(e-mail: abdourafiq12@gmail.com)

*Corresponding Author

\section{INTRODUCTION}

Solitary plasmacytoma is a malignant plasma cell tumor [1]-[3].

Much rarer than multiple myeloma, it is distinguished by its isolated character, its often-slow local evolution and the possibility of cure.

Skull tumors are dominated in frequency by secondary locations. Primary cranial tumors represent less than $2 \%$ of all primary bone tumors [1]. The localization at the level of the vault of the plasmacytoma is extremely rare.

We report the case of a cranial vault plasmacytoma in a 53year-old adult.

\section{OBSERVATION}

A 53-year-old man, having as an antecedent a carnio-facial trauma causing a fracture of the face for which he was operated, consults for tinnitus, left hypoacusia and trigeminal neuralgia of the left V2 and V3 evolving for a year worsened 1 month later by the appearance of a left temporal swelling with reduced visual acuity on the left, without comitiality or motor deficit. On examination, a left temporal swelling of $5 \mathrm{~cm} / 6 \mathrm{~cm}$ fixed in relation to the underlying plane beating without signs of inflammatory opposite. The brain scan found a large mass of tissue density at the left temporal epicenter invading the cavernous sinus and the left sphenoid sinus, the temporal lobe, the masticatory space with lysis of the outer wall of the left orbit, the left para-pharyngeal space, the rock with lysis of the squamous part of the left temporal bone and the presence of an exocranial component (Fig. 1). MRI confirmed the existence of a poorly limited lesion process, with irregular contours, T1 iso signal, T2 hypersignal and flair, intensely and heterogeneously enhanced after injection of gadolinium (Fig. 2). Cerebral arteriography with embolization shows the presence of a tumor-like vascular blush at the left saphenofemoral level, supplied by branches from the left internal maxilla and the ipsilateral posterior little finger. Second, selective catheterization of the branches of the left external carotid artery followed by embolization. The final check shows good lesion devascularization (Fig. 3). After a preanesthesia assessment, the patient underwent partial resection of a very bleeding greyish aspirable lesion. The postoperative follow-up was simple without neurological deterioration. Pathological examination concluded that a plasmacytoma was confirmed by immunostaining. The patient is then referred to the oncology unit for further support. 


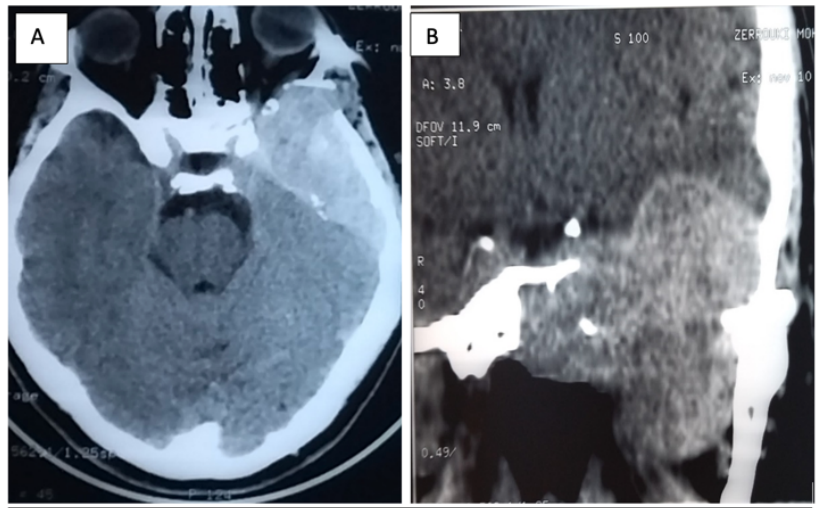

Fig. 1. Brain CT: a voluminous process of tissue density at the left temporal epicenter. A: axial cut B: coronal cut centered on the tumor.

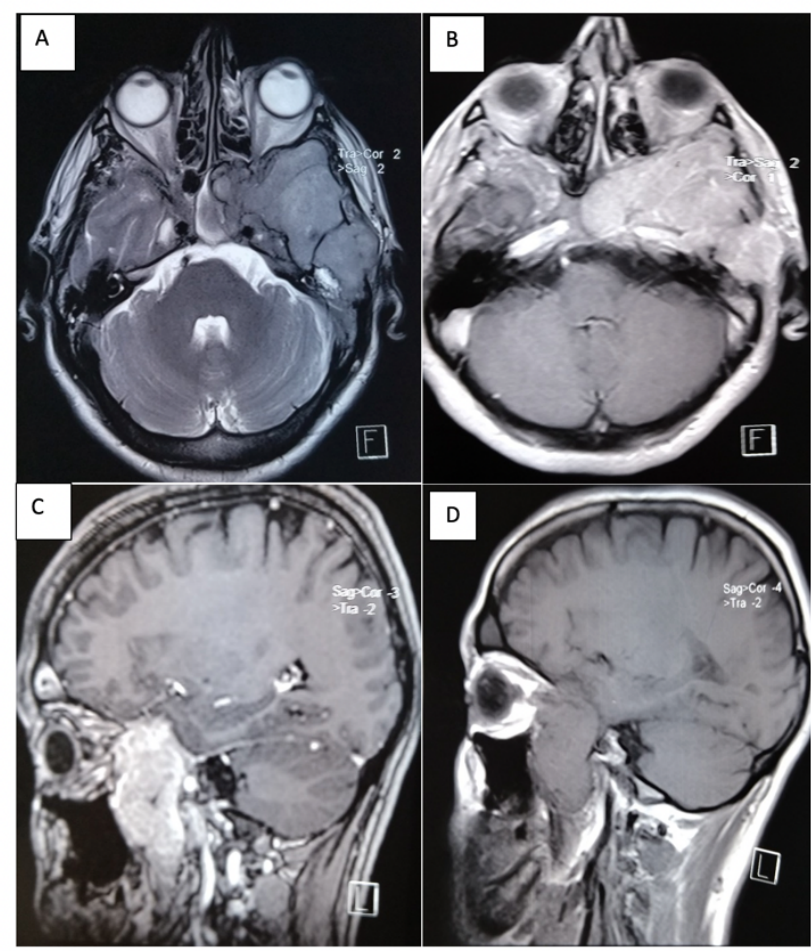

Fig. 2. Left temporal pain lesional process, in T1 iso signal, T2 hypersignal, intensely and heterogeneously enhanced after injection of gadolinium. A: axial section T2; B: axial section T1; C: T1 sagital cut after injection; D: T1 sagital cut without injection.

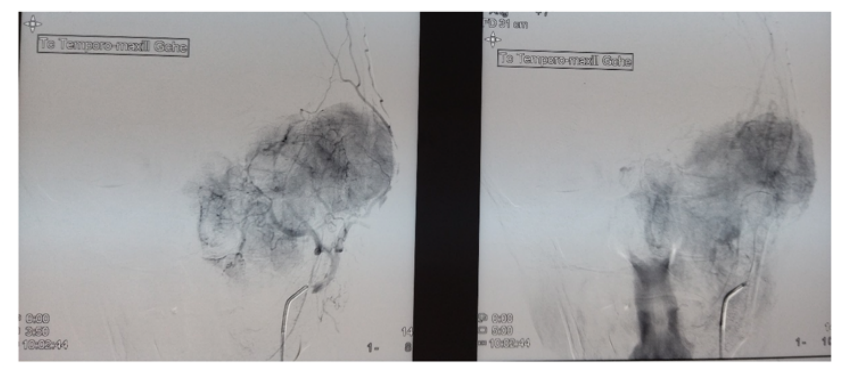

Fig. 3. Arteriography after embolization.

\section{Discussion}

Plasmacytoma is defined as an isolated malignant tumor with plasma cells, without clinical, biological, and radiological signs of myeloma. Craniocerebral localization is rare and constitutes only $0.7 \%$ of all solitary plasmacytomas [4], [5]. Craniocerebral plasmacytoma begins in the dura mater, the bones of the skull or more rarely the brain [4]-[6].
However, the average age of discovery for multiple myelomas is 60 years, while for solitary plasmacytomas it is a young adult between 30 and 50 years old.

The clinical picture reproduces that of an expansive intracranial process of slow evolution without any specificity and according to the site of the tumor.

Solitary bone plasmacytoma is a rarer tumor than multiple myeloma, affecting all bones. The spine is affected in 30 to $40 \%$ of cases, more frequently than long bones and flat bones. Involvement of the cranial vault is very rare [4]-[6] and mainly affects the base of the skull [3], [7]. Up to 2001, 44 cases of solitary intracranial plasmacytomas were reported in the English literature [1]. These are isolated observations of plasmacytoma frequently affecting the parietal bone or sphenoidal localization whereas the Temporal localization, as in the case of our patient, has not been reported. The neuroimaging data of the plasmacytoma are far from being specific, it appears on MRI, in T1 iso-signal with clear enhancement after injection of gadolinium. In addition, the differential diagnoses of temporosphenoidal tumor lesions are extremely varied.

Solitary vault-localized plasmacytoma may be indicative of multiple myeloma but may progress for several years without transformation into multiple myeloma [4]-[8]. Its development is unpredictable. The relationship between plasmacytoma and multiple myeloma is still controversial. For some authors, they constitute two stages of the same pathological process, while for other authors, the solitary plasmacytoma is a well-individualized entity unrelated to multiple myeloma [1], [4].

In all cases, clinical, biological and radiological monitoring remains necessary since more than $85 \%$ of plasmacytoma cases develop genuine Multiple myeloma [9]. Complete tumor excision has never been validated in terms of tumor control and survival and therefore is not recommended. For solitary forms, targeted radiotherapy is the treatment of choice because it provides satisfactory local tumor control, associated with additional chemotherapy in the event of multiple myeloma, as in our case [10], [11].

\section{CONCLUSION}

Cranial plasmacytoma is a rare tumor requiring an associated myeloma. Although the appearance in imaging is not very specific, the plasmacytoma must be considered in the differential diagnosis in front of any invasive lytic lesion of the vault of the skull.

\section{REFERENCES}

[1] Fikri M, Semlali S, El Quessar A, El Hassani MR, Chakir N, Boukhrissi N, et al. Maladie de Kahler révélée par un plasmocytome solitaire de la voûte. Revue Neurologique. 2006; 162(6-7): 757-759. French.

[2] Lakhdar F, Arkha Y, Derraz S, El Ouahabi A, El Khamlichi A. Plasmocytome solitaire intrasellaire révélé par une diplopie: à propos d'un cas. Neurochirurgie. 2012; 58(1): 37-39. French.

[3] Jacquet G, Vuillier J, Viennet A, Godard J, Steimle R. Plasmocytome solitaire simulant un adénome hypothysaire. Neuro-chirurgie (Paris). 1991; 37(1): 67-71.

[4] Khouja N, Aouidj L, Bahri K, Jemel H, Haouet S. Plasmocytome solitaire de la voûte crânienne: A propos d'un cas et revue de la littérature. Neuro-chirurgie (Paris). 2000; 46(1): 43-46. French.

[5] Kuzeyli K, Duru S, Ceylan S, Aktürk F. Solitary plasmacytoma of the skull. A case report. Neurosurgical Review. 1995; 18(2): 139-142. 
[6] Mäntylä R, Kinnunen J, Böhling T. Intracranial plasmacytoma: a case report. Neuroradiology. 1996; 38(7): 646-649.

[7] N'Dri Oka D, Ba Zeze V, Kakou M, Koffi G, Varlet G. Plasmocytome solitaire de la voûte du crâne en Côte-d'Ivoire. Revue Neurologique (Paris). 1998; 154(11). French.

[8] Bindal AK, Bindal RK, van Loveren H, Sawaya R. Management of intracranial plasmacytoma. Journal of Neurosurgery. 1995; 83(2): 218221.

[9] Ustuner Z, Basaran M, Kiris T, Bilgic B, Sencer S, Sakar B, et al. Skull base plasmacytoma in a patient with light chain myeloma. Skull Base. 2003; 13(03): 167-172.

[10] Ampil FL, Borski TG, Nathan CAO, Mulcahy G, Walker M, Chin HW, et al. Cavernous sinus involvement by extramedullary plasmacytoma of the sphenoid sinus. Leukemia \& Lymphoma. 2002; 43(10): 2037 2040.

[11] Yaman E, Benekli M, Coskun U, Sezer K, Ozturk B, Kaya AO, et al. Intrasellar plasmacytoma: an unusual presentation of multiple myeloma. Acta Neurochirurgica. 2008; 150(9): 921-924. 